\title{
In vitro comparison of cyclic fatigue resistance of TruNatomy in single and double curvature canals compared with different nickel-titanium rotary instruments
}

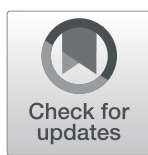

Amr M. Elnaghy ${ }^{1 *}$ D, Shaymaa E. Elsaka ${ }^{2,3}$ and Ayman O. Mandorah ${ }^{4}$

\begin{abstract}
Background: The purpose of this study was to compare the cyclic fatigue resistance of newly developed TruNatomy instruments (TRN) in single and double (S-shaped) curvature canals with HyFlex CM (HCM), Vortex Blue (VB) and RaCe (RC) instruments.

Methods: Size 20/.04 taper and size 25/0.04 of HCM, VB and RC were used. For TRN instruments, size 20/.04 taper (small) and size 26/.04 taper (prime) were used. The instruments were tested in artificial canals with double curvature (coronal curve; $60^{\circ}$ curvature, $5 \mathrm{~mm}$ radius and apical curve; $70^{\circ}$ curvature and $2 \mathrm{~mm}$ radius) and single curvature $\left(60^{\circ}\right.$ curvature, $5 \mathrm{~mm}$ radius). The number of cycles to failure (NCF) was recorded. Data were statistically analyzed by Kruskal-Wallis and Dunn's multiple comparison tests. Weibull analysis was performed on NCF data. Statistical significant was set at $p<0.05$.

Results: TRN and HCM revealed higher NCF compared with the other instruments for both tested sizes in single and double curvature canals $(p<0.05)$. TRN and HCM showed no statistically significant difference in the NCF $(p>0.05)$. The probability of survival was higher for HCM and TRN instruments than VB and RC instruments.

Conclusions: HCM and TRN instruments were more resistant to cyclic fatigue than VB and RC instruments in single and double curvature canals. HCM and TRN instruments were anticipated to survive with higher number of cycles than the other tested instruments. RC instrument had the lowest fatigue resistance than the other instruments.
\end{abstract}

Keywords: Cyclic fatigue, Double curvature, Heat-treated alloy, TruNatomy, Weibull analysis

\section{Background}

In recent years, various thermomechanical treatments of nickel-titanium (NiTi) alloys have been developed to enhance the mechanical properties and clinical performance of NiTi rotary instruments [1-3]. Thermal processing is considered one of the most effective approaches to modify the transition temperatures of NiTi alloys [1, 4]. It has been reported that alterations in the transformation behavior through heat treatment were effectual enhancing the flexibility and fatigue resistance of NiTi endodontic instruments [2, 5-7].

\footnotetext{
* Correspondence: aelnaghy@mans.edu.eg

${ }^{1}$ Department of Endodontics, Faculty of Dentistry, Mansoura University,

Mansoura, PC 35516, Egypt

Full list of author information is available at the end of the article
}

HyFlex CM instruments (HCM) (Coltène-Whaledent, Altstätten, Switzerland) are manufactured using a distinctive method to control material memory through a complex heating and cooling treatment [4]. It has been reported that this heat-treated alloy, together with the distinctive design characteristics of the instruments, enhances the flexibility of the instruments but without the shape memory of conventional superelastic forms of NiTi alloy [8-10]. Consequently, the controlled memory (CM) NiTi instruments allow better maintenance of the original canal curvature and improved the efficacy of instruments in root canal treatment $[9,11]$.

Vortex Blue instrument (VB) (Dentsply Sirona, Ballaigues, Switzerland) is another system that controls the shape memory of NiTi alloy which improved the fatigue resistance of 
the instrument $[2,7,12]$. The manufacturing of VB is based on a proprietary Blue technology that forms a blue oxide layer on the surface of the instrument. The blue titanium oxide layer of $\mathrm{VB}$ is supposed to enhance the cutting efficiency and wear resistance of the instrument $[1,2,7,13]$. The Blue technology allows the instrument to reach the martensitic phase during clinical treatment that enhances the fatigue resistance compared with the other instruments which are mainly in the more rigid austenitic phase [14]. $\mathrm{RaCe}(\mathrm{RC}$; FKG Dentaire, La Chaux-de-Fonds, Switzerland) is an electropolished instrument that is manufactured from a conventional NiTi alloy [15]. The RC instruments have sharp cutting edges to enhance efficiency and alternating cutting edges to remove screwing [16]. Fracture of NiTi rotary instruments is occurred by either flexural or torsional fatigue $[17,18]$. Most of the teeth have curved canals, not only in one but in several orientations and different planes. Double curvatures (S-shaped) root canals can be troublesome and challenging during root canal instrumentation [3]. It has been reported that the fatigue resistance of $\mathrm{NiTi}$ instruments in double curvature canals was lower than in single curvature canals $[3,19]$. Decreasing the probability of NiTi rotary instruments fracture has been one of the main aims of manufacturers in order to enhance safety by using innovative manufacturing processes [20].

Recently, TruNatomy instruments (TRN) (Dentsply Sirona) has been developed as a novel type of heat-treated NiTi instrument with a special design. The TRN shaping instruments are provided in three different sizes which are small (size 20/.04 taper), prime (size 26/.04 taper) and medium (size 36/.03 taper). It has been claimed by the manufacturer that the three shaping instruments of TRN provide a slim shaping which enhances the debridement due to more space is available by this unique design of the instrument. The slim NiTi wire design is $0.8 \mathrm{~mm}$ instead of up to $1.2 \mathrm{~mm}$ of the most other variable tapered instruments. The TRN instruments are off-centred The TRN instruments are off-centred parallelogram cross-section design [21]. It was manufactured by using a special NiTi heat-treated wire that supposed to enhance the flexibility of the instrument. It had been reported that the TRN instruments preserve the structural dentine and tooth integrity due to instrument geometry, regressive tapers and the slim design, along with the heattreatment of the NiTi alloy [21, 22]. There is no data available on the fatigue resistance of TRN instruments. Consequently, the purpose of the present study was to compare the resistance to cyclic fatigue of newly developed TRN in artificial single and double (S-shaped) curvature canals with other NiTi rotary instruments.

\section{Methods}

\section{Cyclic fatigue resistance}

Four NiTi rotary instruments with two different sizes were selected for this study. Size 20/.04 taper and size
25/.04 of HCM, VB and RC were used. For TRN instruments, size 20/.04 taper (small) and size 26/.04 taper (prime) were used. A total of 120 instruments for each system were divided into two groups ( $n=60$ /group) according to the size of the instrument. Then, each group subdivided into two subgroups ( $n=30$ /group) according to the curvature of the canals (single or double). All instruments were subjected to cyclic fatigue testing using a custom-made stainless steel block containing double curvature canal $\left(60^{\circ}\right.$ coronal curvature with a $5 \mathrm{~mm}$ radius and an apical $70^{\circ}$ curvature with a $2 \mathrm{~mm}$ radius) and single curvature canal $\left(60^{\circ}\right.$ curvature with a $5 \mathrm{~mm}$ radius) (Fig. 1) which had been used in previous studies $[3,12,19]$. The instruments were operated in the $\mathrm{X}$ Smart motor (Dentsply Sirona, York, PA, USA) with each specified speed and torque according to the manufacturer. The cyclic fatigue test was performed with instruments immersed in saline at $37 \pm 1{ }^{\circ} \mathrm{C}$. For each instrument, the number of cycles to fracture (NCF) was calculated. The NCF was calculated by multiplying the time recorded in minutes by the recommended motor speed. The fracture length of each instrument fragment was measured. The fractured surface of representative specimens was examined using a scanning electron microscope (SEM) (Stereoscan 260; Cambridge Instruments, Cambridge, UK).

\section{Statistical analysis}

The normality of the data distribution and the homogeneity of variances were tested using KolmogorovSmirnov and Levene tests. The data showed a nonparametric distribution. The NCF and the fractured fragment length data were statistically analyzed by Kruskal-Wallis and Dunn's multiple comparison tests. The MannWhitney test was performed between the data of different sizes of the same instrument. The statistical analysis was performed by using SPSS 20 software (SPSS Inc.,

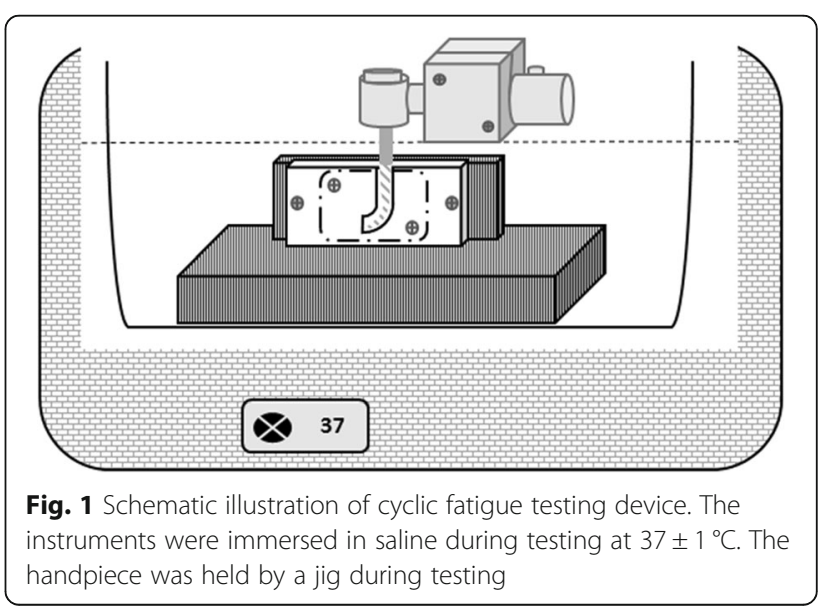


Chicago, IL, USA). The level of significance was set at $p<0.05$. Weibull analysis was performed on NCF data [23-25].

\section{Results}

Table 1 showed the data of NCF and fragment length for TRN, HCM, VB and RC instruments. All the instruments showed significantly higher NCF values for size 20/.04 than size $25 / .04$ in the same curvature $(p<0.05)$. The instruments fractured first in the apical curvature then in the coronal curvature in the double curved canal. TRN and HCM revealed significantly higher NCF compared with the other instruments for both tested sizes in single and double curvature canals $(p<0.05)$. VB had significantly higher NCF than RC for both tested sizes $(p<0.05)$. TRN and HCM showed no significant difference in the NCF $(p>0.05)$. The RC instruments had significantly the lowest NCF values compared with other instruments $(p<$ $0.05)$. There was no significant difference in the fragment length value in all groups $(p>0.05)$. The mean length of broken fragments in single and coronal curvature canals was significantly longer than that of fragments in the apical double curvature canal $(p<0.05)$.

The SEM images of broken segments in the double curvature canal are presented in Fig. 2. All the instruments showed the ductile fracture of cyclic fatigue failure. TRN instrument showed a parallelogram crosssection design while HCM instruments revealed a square cross-section design (Fig. 2a and b; respectively). On the other hand, $\mathrm{VB}$ and $\mathrm{RC}$ instruments revealed triangular cross-section design (Fig. 2c and d; respectively).
The data of Weibull modulus (m), correlation coefficient $\left(R^{2}\right)$, characteristic strength $\left(\sigma_{0}\right)$ and predicted cycles for $99 \%$ survival for the NCF data for each group are presented in Table 2 . The cumulative probability of survival plots for the NCF data of the tested instruments are presented in Fig. 3. The instruments with size 20/.04 taper (Fig. 3a-c) revealed higher reliability than instruments with a size 25/.04 taper (Fig. 3d-f). HCM and TRN instruments showed higher reliability compared with VB and RC instruments. The predicted cycles for 99\% survival of instruments tested in single curvature were higher than the instruments tested in the double curvature canal (Table 2).

\section{Discussion}

Various factors can affect the fracture resistance of NiTi rotary instruments including alloy composition, manufacturing methods, cross-sectional geometry and flute design [26, 27]. Thermomechanical technology is commonly used for improving the microstructure and transformation behaviors of NiTi instruments in order to enhance the performance of instruments during root canal shaping including the cyclic fatigue resistance [28, 29]. In the present study, HCM and TRN instruments showed greater cyclic fatigue resistance than VB and RC instruments. HCM instruments are manufactured from $\mathrm{CM}$ heat-treated alloy that controls the instrument memory [4], which allows superior maintenance of the original canal curvature and enhanced the efficiency of the instrument in root canal preparation $[9,11]$. HCM instruments are characterized by a triangular cross-

Table 1 Mean \pm standard deviations, median of number of cycles to failure (NCF), and length (mm) of fractured fragments (FL) of tested instruments

\begin{tabular}{|c|c|c|c|c|c|c|c|c|c|}
\hline \multirow[t]{4}{*}{ Groups } & \multirow{2}{*}{\multicolumn{3}{|c|}{ Single curvature }} & \multicolumn{6}{|c|}{ Double curvature } \\
\hline & & & & \multicolumn{3}{|c|}{ Apical curvature } & \multicolumn{3}{|c|}{ Coronal curvature } \\
\hline & \multicolumn{2}{|l|}{ NCF } & \multirow{2}{*}{$\begin{array}{l}\mathrm{FL} \\
\text { Mean } \pm \mathrm{SD}\end{array}$} & \multicolumn{2}{|l|}{ NCF } & \multirow{2}{*}{$\begin{array}{l}F L \\
\text { Mean } \pm S D\end{array}$} & \multicolumn{2}{|l|}{ NCF } & \multirow{2}{*}{$\begin{array}{l}\mathrm{FL} \\
\text { Mean } \pm S D\end{array}$} \\
\hline & Mean \pm SD & Median & & Mean \pm SD & Median & & Mean \pm SD & Median & \\
\hline \multicolumn{10}{|l|}{ TRN } \\
\hline $20 / .04$ & $1327.4 \pm 100.7^{\mathrm{A}}$ & 1317 & $5.17 \pm 0.14$ & $619.2 \pm 52.3^{A}$ & 629 & $2.12 \pm 0.07$ & $719.6 \pm 79.4^{\mathrm{A}}$ & 716 & $5.07 \pm 0.15$ \\
\hline $26 / .04$ & $1238.8 \pm 106.7^{\mathrm{a}}$ & 1277 & $5.17 \pm 0.13$ & $532.8 \pm 51.9^{a}$ & 523 & $2.12 \pm 0.06$ & $609.2 \pm 46.5^{\mathrm{a}}$ & 614 & $5.05 \pm 0.14$ \\
\hline \multicolumn{10}{|l|}{$\mathrm{HCM}$} \\
\hline $20 / .04$ & $1388.1 \pm 101.9^{A}$ & 1362 & $5.15 \pm 0.11$ & $623.9 \pm 57.4^{\mathrm{A}}$ & 629 & $2.11 \pm 0.09$ & $737.8 \pm 73.1^{\mathrm{A}}$ & 715 & $5.08 \pm 0.19$ \\
\hline $25 / .04$ & $1296.3 \pm 80.3^{a}$ & 1265 & $5.18 \pm 0.18$ & $542.6 \pm 52.4^{a}$ & 544 & $2.13 \pm 0.17$ & $618.6 \pm 51.4^{a}$ & 621 & $5.07 \pm 0.19$ \\
\hline \multicolumn{10}{|l|}{ VB } \\
\hline $20 / .04$ & $704.3 \pm 55.1^{B}$ & 712 & $5.14 \pm 0.21$ & $447.3 \pm 71.7^{B}$ & 430 & $2.16 \pm 0.11$ & $540.4 \pm 55.3^{B}$ & 549 & $5.04 \pm 0.25$ \\
\hline $25 / .04$ & $529.5 \pm 56.8^{b}$ & 516 & $5.16 \pm 0.21$ & $290.2 \pm 33.5^{b}$ & 290 & $2.15 \pm 0.17$ & $358.4 \pm 44.1^{b}$ & 351 & $5.08 \pm 0.22$ \\
\hline \multicolumn{10}{|l|}{$\mathrm{RC}$} \\
\hline $20 / .04$ & $232.3 \pm 29.5^{C}$ & 230 & $5.13 \pm 0.07$ & $122.5 \pm 20.7^{C}$ & 125 & $2.13 \pm 0.17$ & $140.1 \pm 21.1^{C}$ & 140 & $5.04 \pm 0.15$ \\
\hline $25 / .04$ & $215.9 \pm 22.4^{c}$ & 215 & $5.14 \pm 0.08$ & $93.1 \pm 12.1^{c}$ & 95 & $2.14 \pm 0.17$ & $127.7 \pm 15.1^{c}$ & 126 & $5.03 \pm 0.18$ \\
\hline
\end{tabular}

Different superscript uppercase letter (column) for instrument size 20/.04 and lowercase letter (column) for sizes 25/.04 and 26/.04 indicate statistically significant difference $(P<0.05)$ 

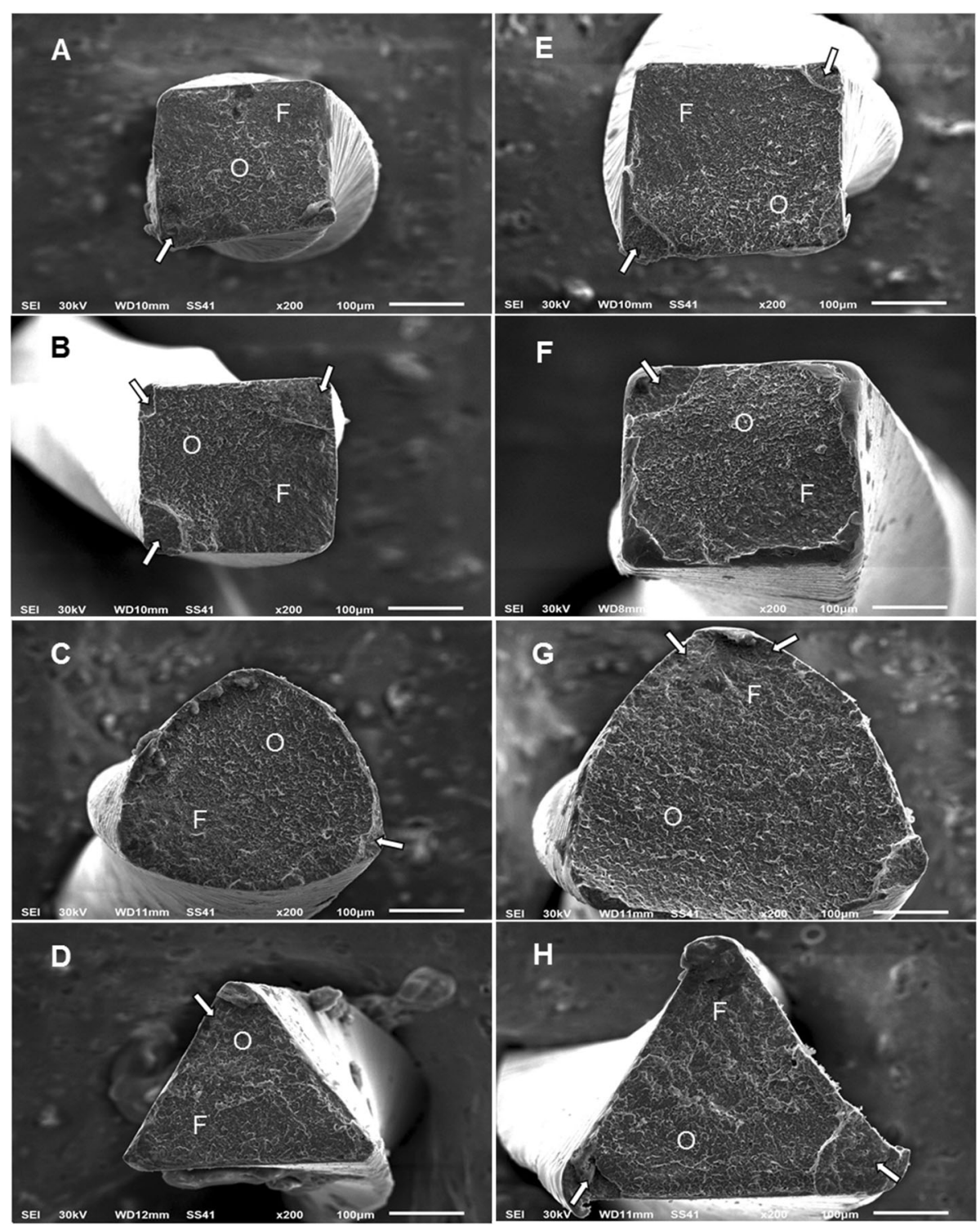

Fig. 2 SEM images $(\times 200)$ of fractured fragments in double curvature canals. Fracture of instruments in apical curvature (a-d) and coronal curvature (e-h). (a, e) TRN, (b, f) HCM, (c, g) VB and ( $\mathbf{d}, \mathbf{h})$ RC; respectively. The following features could be observed: the origin of the crack (arrow), fatigue zone $(\mathbf{f})$, and overload fast fracture zone (o)

sectional design displaying three cutting edges except for the instruments with size 20/.04 and 25/.04 taper, which have a square cross-section design with four blades and four flutes [30] as in the present study (Fig. 2b).

The newly developed TRN instruments are manufactured from heat-treated NiTi alloy that supposed to enhance the flexibility and fatigue resistance of the instrument [22]. TRN instruments revealed a parallelogram cross-section design (Fig. 2a) while HCM showed a square cross-section design (Fig. 2b). Both HCM and TRN instruments revealed enhanced fatigue resistance with no significant difference between them. This finding could be attributed to the manufacturing process as
HCM and TRN instruments are manufactured from heat-treated NiTi alloy. The thermomechanical treatment of endodontic instruments produced instrument with different austenite finishing temperature (Af), which affects the mechanical properties especially the fatigue resistance and bending properties [31, 32]. The heat treatment of HCM instrument is based on shifting the austenite/martensite transition temperature so that a stable martensitic microstructure is obtained at body temperature [32]. Although $\mathrm{HCM}$ and VB instruments are manufactured from heat-treated $\mathrm{NiTi}$ alloy, the HCM instrument had a higher fatigue resistance. It had been reported that VB instruments had a higher degree 


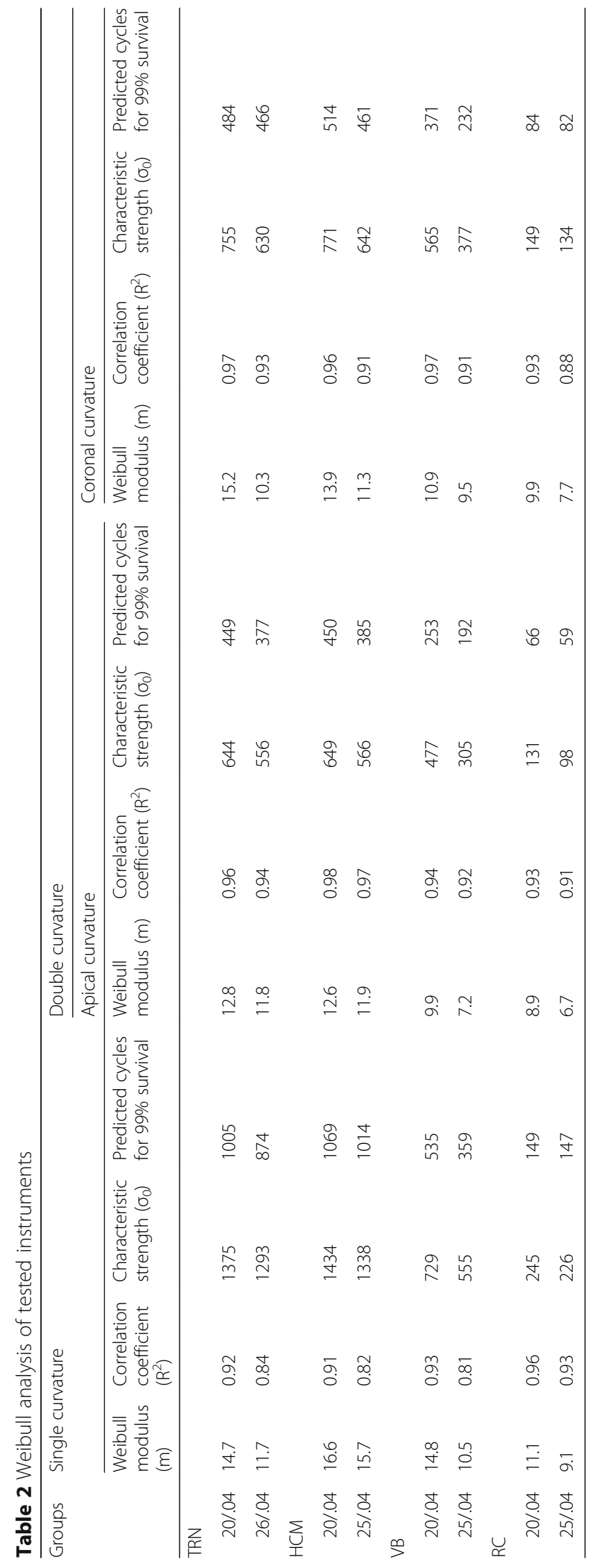



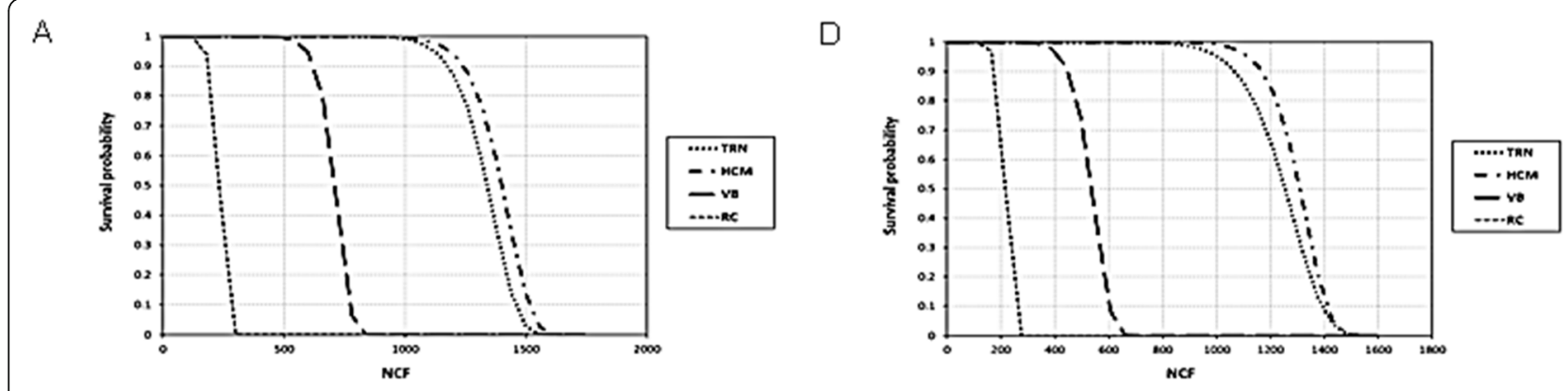

$\mathrm{B}$

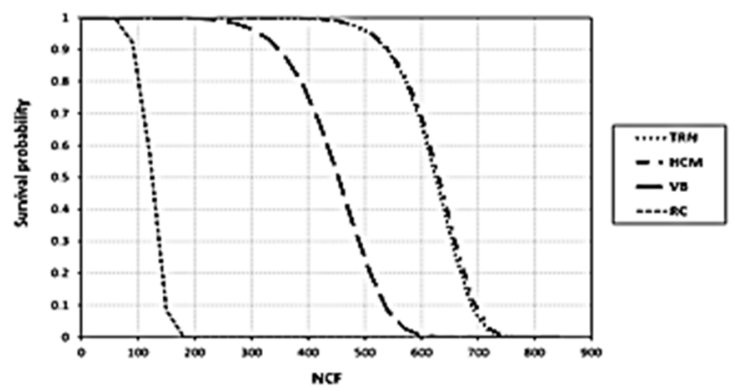

$\mathrm{C}$

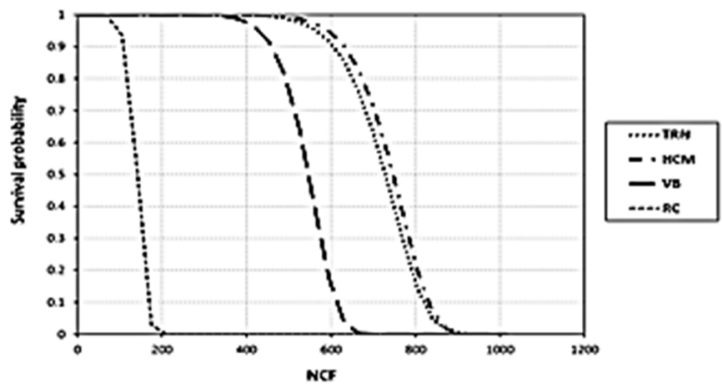

E

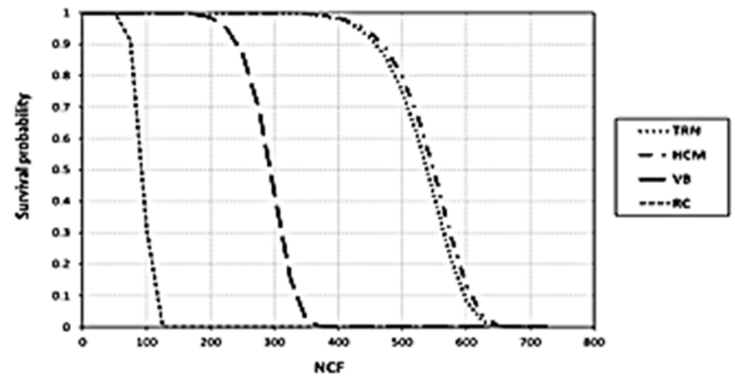

$\mathrm{F}$

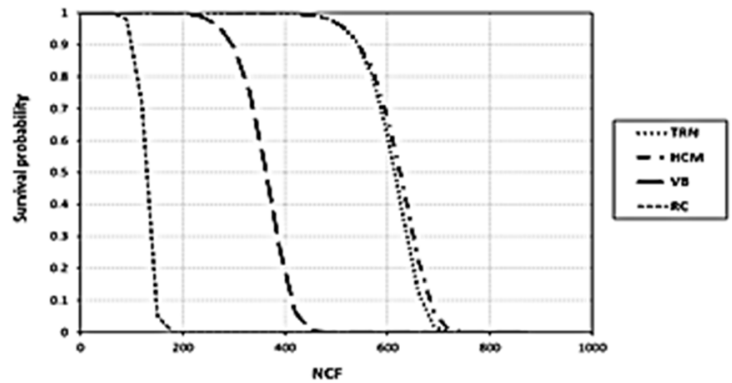

Fig. 3 Survival probability plots for TRN, HCM, VB and RC instruments in single and double curvature canals. (a-c) Instruments with size 20/.04 taper for single, double apical and double coronal curvatures; respectively. (d-f) Instruments with size 25/.04 taper for single, double apical and double coronal curvatures; respectively

of austenite than HCM instruments at body temperature [33]. It could be postulated that HCM and TRN instruments might be used more safely in curved canals with double curvature due to their superior fatigue resistance.

TRN instruments revealed higher fatigue resistance than VB and RC instruments. This finding could be attributed to the special heat treatment of the alloy and the design of the instruments that enhanced fatigue resistance. Heat treatment of the alloy enhances the arrangement of the crystal structure, which might improve the flexibility and strength of the NiTi instruments [10]. In addition, heat treatments of NiTi instruments during or after the manufacturing process reducing the internal stress and surface defects due to the grinding process [10].

VB instruments showed superior fatigue resistance than $\mathrm{RC}$ instruments. VB instrument is manufactured from NiTi Blue alloy with a reduced shape memory characteristic which improved the fatigue resistance of the instrument $[2,7,12]$. On the other hand, the RC instrument is manufactured from conventional NiTi alloy that influenced the fatigue resistance of the instrument $[2,12]$. RC instruments revealed the lowest fatigue resistance among the tested instruments.

The double curvature canals (S-shaped) created more stress on NiTi rotary instruments than in single curvature canals, and consequently, the instruments fractured due to cyclic fatigue $[12,19,29]$. The S-shaped canal is one of the most challenging conditions in clinical situations during root canal instrumentation with NiTi rotary instruments [19]. In many cases, the double curvatures are not detected in conventional radiographs; consequently, the clinician should be cautious of this probability and continue carefully during root canal instrumentation [3]. In the double curvature canal, the instruments fractured first in the apical curvature followed by the coronal curvature. This finding could be attributed to the abrupt curvature in the apical area with a $2 \mathrm{~mm}$ radius compared with the coronal curvature with a $5 \mathrm{~mm}$ radius, which is in agreement with the previous studies [3, 19, 34]. There was no significant difference in the mean length of the 
broken fragments of tested instruments in the same curvature. The instruments fractured at or just below the centre of curvature, which is in agreement with the previous studies [3, 12,34].

The Weibull analysis revealed that the instruments with size 20/.04 taper revealed higher reliability than instruments with size 25/.04 taper. The instruments tested in a single curvature canal revealed higher predicted cycles for 99\% survival compared with instruments tested in the double curvature canal. The probability of survival was higher for HCM and TRN instruments than VB and $\mathrm{RC}$ instruments. RC instruments had the lowest predicted number of cycles compared with the other groups. Weibull analysis is an appropriate method to predict the survival probability of NiTi rotary instruments $[24,35]$.

\section{Conclusions}

HCM and TRN had superior fatigue resistance than VB and RC in single and double curvature canals. HCM and TRN instruments were anticipated to survive with higher number of cycles than the other tested instruments. RC had the lowest fatigue resistance than other instruments.

\section{Abbreviations \\ Af: Austenite finishing temperature; CM: Controlled memory; HCM: HyFlex CM; m: Weibull modulus; NCF: Number of cycles to failure; NiTi: Nickel- titanium; R²: Correlation coefficient; RC: RaCe; SEM: Scanning electron microscope; TRN: TruNatomy; VB: Vortex Blue; $\sigma_{0}$ : Characteristic strength}

\section{Acknowledgements}

Not applicable.

\section{Authors' contributions}

$\mathrm{AE}, \mathrm{SE}$, and $\mathrm{AM}$ were responsible for the concept, design and implementation of the work, analyzed the participant data and interpretation of data. AE and SE were major contributors in writing the manuscript. All authors read and approved the final manuscript.

\section{Funding}

There was no funding for this study.

\section{Availability of data and materials}

The datasets used and/or analysed during the current study are available from the corresponding author on reasonable request.

\section{Ethics approval and consent to participate}

Not applicable.

\section{Consent for publication}

Not applicable.

\section{Competing interests}

The authors declare that they have no competing interests.

\section{Author details}

${ }^{1}$ Department of Endodontics, Faculty of Dentistry, Mansoura University, Mansoura, PC 35516, Egypt. ${ }^{2}$ Department of Dental Biomaterials, Faculty of Dentistry, Mansoura University, Mansoura, Egypt. ${ }^{3}$ Department of Restorative Science, Alfarabi Private College for Dentistry and Nursing, Jeddah, Saudi Arabia. ${ }^{4}$ Department of Restorative and Dental Materials, Faculty of Dentistry, Taif University, Taif, Saudi Arabia.
Received: 30 August 2019 Accepted: 29 January 2020

Published online: 04 February 2020

\section{References}

1. Shen Y, Zhou HM, Zheng YF, Peng B, Haapasalo M. Current challenges and concepts of the thermomechanical treatment of nickel-titanium instruments. J Endod. 2013;39(2):163-72.

2. Gao Y, Gutmann JL, Wilkinson K, Maxwell R, Ammon D. Evaluation of the impact of raw materials on the fatigue and mechanical properties of ProFile vortex rotary instruments. J Endod. 2012;38(3):398-401.

3. Duke F, Shen Y, Zhou H, Ruse ND, Wang ZJ, Hieawy A, Haapasalo M. Cyclic fatigue of Profile vortex and vortex blue nickel-titanium files in single and double curvatures. J Endod. 2015;41(10):1686-90.

4. Gutmann JL, Gao Y. Alteration in the inherent metallic and surface properties of nickel-titanium root canal instruments to enhance performance, durability and safety: a focused review. Int Endod J. 2012;45(2):113-28.

5. Hayashi Y, Yoneyama T, Yahata Y, Miyai K, Doi H, Hanawa T, Ebihara A, Suda H. Phase transformation behaviour and bending properties of hybrid nickeltitanium rotary endodontic instruments. Int Endod J. 2007:40(4):247-53.

6. Yahata Y, Yoneyama T, Hayashi Y, Ebihara A, Doi H, Hanawa T, Suda H. Effect of heat treatment on transformation temperatures and bending properties of nickel-titanium endodontic instruments. Int Endod J. 2009; 42(7):621-6.

7. Plotino G, Grande NM, Cotti E, Testarelli L, Gambarini G. Blue treatment enhances cyclic fatigue resistance of vortex nickel-titanium rotary files. J Endod. 2014;40(9):1451-3.

8. Elnaghy AM, Elsaka SE. Cyclic fatigue resistance of XP-endo shaper compared with different nickel-titanium alloy instruments. Clin Oral Investig. 2018;22(3):1433-7.

9. Peters OA, Gluskin AK, Weiss RA, Han JT. An in vitro assessment of the physical properties of novel Hyflex nickel-titanium rotary instruments. Int Endod J. 2012:45(11):1027-34.

10. Plotino G, Testarelli L, Al-Sudani D, Pongione G, Grande NM, Gambarini G. Fatigue resistance of rotary instruments manufactured using different nickel-titanium alloys: a comparative study. Odontology. 2014;102(1):31-5.

11. Zhao D, Shen Y, Peng B, Haapasalo M. Micro-computed tomography evaluation of the preparation of mesiobuccal root canals in maxillary first molars with Hyflex CM, twisted files, and K3 instruments. J Endod. 2013; 39(3):385-8.

12. Elnaghy AM, Elsaka SE. Cyclic fatigue resistance of one curve, 2Shape, Profile vortex, vortex blue, and RaCe nickel-titanium rotary instruments in single and double curvature canals. J Endod. 2018;44(11):1725-30.

13. Dentsply Sirona. Vortex Blue Brochure. Available at: https://www. dentsplysirona.com/content/dam/dentsply/pim/manufacturer/Endodontics/ Glide_Path_Shaping/Rotary__Reciprocating_Files/Shaping/Nortex_Blue_ Rotary_Files/Nortex-Blue-bng4uld-en-1402 Accessed April 15, 2019.

14. Gambarini G, Galli M, Di Nardo D, Seracchiani M, Donfrancesco O, Testarelli L. Differences in cyclic fatigue lifespan between two different heat treated NiTi endodontic rotary instruments: WaveOne gold vs EdgeOne fire. J Clin Exp Dent. 2019;11(7):e609-13.

15. Keskin NB, Inan U. Cyclic fatigue resistance of rotary NiTi instruments produced with four different manufacturing methods. Microsc Res Tech. 2019;82(10):1642-8.

16. Aydin C, Inan U, Tunca YM. Comparison of cyclic fatigue resistance of used and new RaCe instruments. Oral Surg Oral Med Oral Pathol Oral Radiol Endod. 2010;109(3):e131-4.

17. Sattapan B, Nervo GJ, Palamara JE, Messer HH. Defects in rotary nickeltitanium files after clinical use. J Endod. 2000;26(3):161-5.

18. Ullmann CJ, Peters OA. Effect of cyclic fatigue on static fracture loads in ProTaper nickel-titanium rotary instruments. J Endod. 2005;31(3):183-6.

19. Al-Sudani D, Grande NM, Plotino G, Pompa G, Di Carlo S, Testarelli L, Gambarini G. Cyclic fatigue of nickel-titanium rotary instruments in a double (S-shaped) simulated curvature. J Endod. 2012;38(7):987-9.

20. Shen Y, Hieawy A, Huang X, Wang ZJ, Maezono H, Haapasalo M. Fatigue resistance of a 3-dimensional conforming nickel-titanium rotary instrument in double curvatures. J Endod. 2016;42(6):961-4.

21. Van der Vyver PJ, Vorster M, Peters OA. Minimally invasive endodontics using a new single-file rotary system. Int Dent - African ed. 2019;9(4):6-20.

22. Dentsply Sirona. TruNatomy Brochure. Available at: https://www. dentsplysirona.com/en/explore/endodontics/trunatomy.html Accessed April 26, 2019. 
23. Weibull W. A statistical distribution function of wide applicability. J Appl Mech. 1951;128:293-7.

24. Nguyen $\mathrm{HH}$, Fong $\mathrm{H}$, Paranjpe A, Flake NM, Johnson JD, Peters OA. Evaluation of the resistance to cyclic fatigue between ProTaper next, ProTaper universal, and vortex blue rotary instruments. J Endod. 2014;40: 1190-3.

25. Elsaka SE, Elnaghy AM. Cyclic fatigue resistance of OneShape and WaveOne instruments using different angles of curvature. Dent Mater J. 2015;34:358-63.

26. Kim HC, Yum J, Hur B, Cheung GS. Cyclic fatigue and fracture characteristics of ground and twisted nickel-titanium rotary files. J Endod. 2010;36(1):147-52.

27. Kim TO, Cheung GS, Lee JM, Kim BM, Hur B, Kim HC. Stress distribution of three NiTi rotary files under bending and torsional conditions using a mathematic analysis. Int Endod J. 2009:42(1):14-21.

28. Hieawy A, Haapasalo M, Zhou H, Wang ZJ, Shen Y. Phase transformation behavior and resistance to bending and cyclic fatique of ProTaper gold and ProTaper universal instruments. J Endod. 2015;41(7):1134-8.

29. Uslu G, Özyürek T, Yilmaz K, Gündoğar M. Cyclic fatique resistance of R-pilot, HyFlex EDM and PathFile nickel-titanium glide path files in artificial canals with double (S-shaped) curvature. Int Endod J. 2018;51(5):584-9.

30. Bürklein S, Börjes L, Schäfer E. Comparison of preparation of curved root canals with Hyflex CM and Revo-S rotary nickel-titanium instruments. Int Endod J. 2014:47(5):470-6.

31. Hou X, Yahata Y, Hayashi Y, Ebihara A, Hanawa T, Suda H. Phase transformation behaviour and bending property of twisted nickel-titanium endodontic instruments. Int Endod J. 2011;44(3):253-8.

32. Santos Lde A, Bahia MG, de Las Casas EB, Buono VT. Comparison of the mechanical behavior between controlled memory and superelastic nickeltitanium files via finite element analysis. J Endod. 2013;39(11):1444-7.

33. de Vasconcelos RA, Murphy S, Carvalho CA, Govindjee RG, Govindjee S, Peters OA. Evidence for reduced fatigue resistance of contemporary rotary instruments exposed to body temperature. J Endod. 2016;42(5):782-7.

34. Topçuoğlu HS, Topçuoğlu G, Düzgün S. Resistance to cyclic fatigue of PathFile, ScoutRaCe and ProGlider glide path files in an S-shaped canal. Int Endod J. 2018;51(5):509-14.

35. Arias A, Perez-Higueras JJ, de la Macorra JC. Differences in cyclic fatigue resistance at apical and coronal levels of Reciproc and WaveOne new files. J Endod. 2012;38(9):1244-8.

\section{Publisher's Note}

Springer Nature remains neutral with regard to jurisdictional claims in published maps and institutional affiliations.

Ready to submit your research? Choose BMC and benefit from:

- fast, convenient online submission

- thorough peer review by experienced researchers in your field

- rapid publication on acceptance

- support for research data, including large and complex data types

- gold Open Access which fosters wider collaboration and increased citations

- maximum visibility for your research: over $100 \mathrm{M}$ website views per year

At $\mathrm{BMC}$, research is always in progress.

Learn more biomedcentral.com/submissions 